\title{
Families At Risk - Perception Of Professionals Working In Public And Civil Sector
}

\author{
Ivana Jeđud Borić, Anja Mirosavljević, Andrea Ćosić \\ University of Zagreb, Faculty of Education and Rehabilitation Sciences \\ Department of Behavioural Disorders
}

\begin{abstract}
Previous research findings indicate that intervention systems for children, youth and adults in risk should focus simultaneously on the individual with the problem and his/her family. Therefore, gaining new knowledge on families at risk and development of new interventions and services present a permanent research and professional challenge. This research is supplement of bigger study "Specific characteristics of families at risk: contribution to complex interventions planning - FamResPlan", funded by the Croatian Science Foundation. The objective of this research was to gain insight into experiences and perspective of professionals working with families at risk, concerning following characteristics of the families: resilience, readiness for change and readiness for intervention. Two groups of professionals were included in study- those working in public sector (social welfare center) and those working in civil sector. Data were collected through focus groups in specific neighborhood in Zagreb. Participants were mainly female, working closely with families at risk. The data were analysed using thematic analysis. Results show that professionals recognized spectrum of complex needs of families at risk, concerning individual needs of certain family members, but also of family. The existing intervention system is characterized as inadequate to meet those needs, especially in public sector that often lacks basic resources. The nongovernmental sector is perceived as more flexible and progressive. Perspective of professionals who work directly with families is important not only for practical reasons (creating interventions) but also from methodological aspect in planning further research with families. Lesson learned from professionals is that research should be supported by immediate intervention for certain family.
\end{abstract}

Keywords: complex needs; families; risk; professional's perception; 